\title{
Stimulated Human Lamina Propria T Cells Manifest Enhanced Fas-mediated Apoptosis
}

\author{
Monica Boirivant, ${ }^{\star}$ Roberta Pica, ${ }^{\ddagger}$ Ruggero DeMaria, ${ }^{\S}$ Roberto Testi, ${ }^{\S}$ Francesco Pallone, and Warren Strober ${ }^{\llbracket}$ \\ *Immunology Department, Istituto Superiore di Sanità, Rome, Italy; ${ }^{\ddagger}$ GI Unit, II Clinica Medica, Università La Sapienza, Rome, Italy; \\ ${ }^{\S}$ Department of Experimental Medicine and Biochemical Sciences, University of Rome Tor Vergata, Rome, Italy; $\|$ Department of \\ Experimental Medicine, University of Reggio Calabria, Catanzaro, Italy; ${ }^{\mathbb{T}}$ Mucosal Immunity Section, Laboratory of Clinical \\ Investigation, National Institute of Allergy and Infectious Diseases, National Institutes of Health, Bethesda, Maryland
}

\begin{abstract}
Lamina propria (LP) $\mathrm{T}$ cells respond poorly to a proliferative stimulus delivered via TCR/CD3 pathway, but retain considerable ability to respond to a stimulus delivered via CD2 costimulatory or accessory pathway. In the present study, we showed first that unstimulated LP T cells, as compared to unstimulated peripheral blood (PB) $\mathrm{T}$ cells, exhibit an increased level of apoptosis which is further increased following CD2 pathway stimulation, but not following via TCR/CD3 pathway stimulation. We next showed that IL-2 had a sparing effect on apoptosis of unstimulated LP T cells in that IL-2 decreased and anti-IL-2 increased apoptosis of these cells; in contrast, IL-2 had no effect on apoptosis of CD2-pathway stimulated cells. Finally, we showed that increased apoptosis of LP T cells induced by CD2-pathway stimulation is inhibited when Fas antigen is blocked by a nonstimulatory anti-Fas antibody. These studies suggest that LP T cells are characterized by increased susceptibility to Fas-mediated apoptosis most due to a downstream change in the Fas signaling pathway. Given that IFN- $\gamma$ secretion is significantly increased in LP T cells in which apoptosis is inhibited, this feature of LP T cells may represent a mechanism of regulating detrimental immune responses in the mucosal environment. (J. Clin. Invest. 1996. 98:26162622.) Key words: apoptosis • T lymphocytes • human • intestinal lamina propria $\bullet$ regional immunity
\end{abstract}

\section{Introduction}

Despite the fact that lamina propria (LP) ${ }^{1} \mathrm{~T}$ cells are in close proximity to potentially stimulatory mucosal antigens, and exhibit increased expression of surface markers of cell activation

Address correspondence to Monica Boirivant, M.D., Immunology Department, Istituto Superiore di Sanita, Viale Regina Elena 299, 00161 Rome, Italy. Phone: 39-6-499-02976; FAX: 39-6-493-87115.

Received for publication 19 April 1996 and accepted in revised form 27 September 1996.

1. Abbreviations used in this paper: LP, lamina propria; LPMC, lamina propria mononuclear cells; PBMC, peripheral blood mononuclear cells.

J. Clin. Invest.

(c) The American Society for Clinical Investigation, Inc. 0021-9738/96/12/2616/07 \$2.00

Volume 98, Number 11, December 1996, 2616-2622
$(1,2)$, the lamina propria is a site of controlled chronic inflammation normally $(3,4)$. One immunologic mechanism that may at least partially explain this state of affairs involves the possibility that LP T cells are subject to immunologically induced programmed cell death (apoptosis) and are thus eliminated before they can mediate a deleterious immune response. Support for this possibility comes from previous studies in which it was shown that vigorous stimulation of $\mathrm{T}$ cells with superantigens is followed by programmed cell death, which then prevents clonal expansion of potentially disease-producing $\mathrm{T}$ and $B$ cells $(5,6)$. In addition, the regulation of immune responses in the lamina propria via apoptosis is supported by the fact that activated cells are at greater risk for TCR/CD3-induced apoptosis $(7,8)$ and that such apoptosis does not in itself elicit an inflammatory response (9).

Recent studies in which the activation and subsequent function of LP T cells has been characterized in some detail (10-13) also bear on the issue of LP T cell apoptosis. These show that LP T cells manifest proliferative hyporesponsiveness when stimulated via the TCR/CD3 signaling pathway, but relative normoresponsiveness when stimulated via the CD2 accessory signaling pathway, as compared to peripheral blood (PB) $\mathrm{T}$ cells (10-12). This pattern of hyporesponsiveness is highlighted by the fact that in chronic inflammatory bowel disease, TCR/CD3 pathway unresponsiveness is further increased whereas CD2 pathway normoresponsiveness is maintained (14). Inasmuch as T cell unresponsiveness and susceptibility for apoptosis appears to occur coordinately in some systems (6), it is reasonable to propose that LP T cells are characterized by an increased apoptosis.

In the present study, we investigated apoptosis in the LP T cell population by measuring apoptosis in unstimulated and stimulated LP T cells. We demonstrated that unstimulated LP $\mathrm{T}$ cells exhibited an increased level of apoptosis, which is greatly enhanced by stimulation of cells via the CD2 pathway but not the TCR/CD3 pathway. Moreover, we showed that the increased apoptosis of CD2-pathway stimulated LP T cells is mediated by the Fas signaling pathway.

\section{Methods}

Intestinal and peripheral mononuclear cells. Intestinal mononuclear cells and $\mathrm{T}$ cells were extracted from surgical specimens obtained from 23 surgical patients admitted for bowel resection (to the Università degli Studi La Sapienza, Rome), for malignant and nonmalignant conditions. Among these, 15 had sigmoid carcinoma, 5 had right colon carcinoma, and the remaining 3 patients had diverticular disease. Mucosal samples were obtained from macroscopically and microscopically unaffected areas.

Lamina propria mononuclear cells (LPMC) were isolated from freshly resected mucosa using a previously described DDT-EDTAcollagenase method (15). In brief, strips of mucosa (6-8 g total weight) 
were washed in HBBS free of calcium and magnesium (HBSS-CMF; Hyclone, Europe LTD, Cramlington, UK). They were then washed in HBSS-CMF containing $1 \mathrm{mmol} /$ liter DTT (Sigma Chemical Co., St. Louis, MO) and antibiotics (penicillin, $100 \mathrm{U} / \mathrm{ml}$; streptomycin, 100 $\mu \mathrm{g} / \mathrm{ml}$; gentamicin, $50 \mu \mathrm{g} / \mathrm{ml}$; and fungizone, $25 \mu \mathrm{g} / \mathrm{ml}$ ) for $15 \mathrm{~min}$ at room temperature. After three washings in HBSS-CMF, the mucosal strips were chopped into pieces (approximately $3 \times 3 \mathrm{~mm}$ ) and incubated four to five times in HBSS-CMF containing $0.75 \mathrm{mmol} / \mathrm{liter}$ EDTA, $10 \mathrm{mmol} /$ liter HEPES buffer, and antibiotics for $45 \mathrm{~min}$ at $37^{\circ} \mathrm{C}$ in a humid $5 \% \mathrm{CO}_{2}$ atmosphere to remove epithelial cells. After two washes, the pieces were incubated for $10-13 \mathrm{~h}$ at $37^{\circ} \mathrm{C}$ in a humid $5 \% \mathrm{CO}_{2}$ atmosphere in complete medium (RPMI 1640 plus $10 \mathrm{mM}$ HEPES buffer, $2 \mathrm{mM}$ l-glutamine, 10\% heat-inactivated FCS (Hyclone), and antibiotics) containing $25 \mathrm{U} / \mathrm{ml}$ collagenase V (Sigma Chemical Co.). After incubation, the supernatant was collected and washed twice in HBSS-CMF, and LPMC were isolated on a Percoll (Sigma Chemical Co.) gradient.

Autologous peripheral blood mononuclear cells (PBMC) were isolated from venous heparinized blood obtained from individuals immediately before surgery. Mononuclear cells were separated from other cellular elements by layering on a Ficoll-Paque density gradient. Purified T cells were obtained from PBMC and LPMC by immunomagnetic negative selection using immunomagnetic beads coated with anti-CD14 and anti-CD20 mouse anti-human mAb (Dynal, Oslo, Norway). The resultant (unbound) $\mathrm{T}$ cell population contained greater than $95 \% \mathrm{CD} 3+$ cells as assessed by flow cytometric analysis. PB T cells were further depleted of CD45RA+ cells using immunomagnetic beads coated with goat anti-mouse IgG after incubation of cells with anti-CD45RA mouse anti-human mAb (Clone 2H4; Coulter Immunology, Hialeah, FL).

Proliferation assays. To measure proliferation, PBMC or LPMC $\left(5 \times 10^{4}\right.$ cells $)$ were cultured in $0.2 \mathrm{ml}$ of complete medium with different stimuli (see below) in flat-bottomed, 96-well microtiter plates (Falcon Labware, Becton Dickinson \& Co., Lincoln Park, NJ). Cultures were incubated at $37^{\circ} \mathrm{C}$ in a humidified incubator containing $5 \%$ $\mathrm{CO}_{2}$ for $72 \mathrm{~h} ; 15 \mathrm{~h}$ before terminating the culture, $1 \mathrm{mCi}$ of $\left[{ }^{3} \mathrm{H}\right]$ thymidine (DuPont-NEN, Boston, MA) was added to each microwell. Cells were harvested and counted in a liquid scintillation counter.

Cell cultures. Cells $\left(1 \times 10^{6}\right)$ were resuspended in $1 \mathrm{ml}$ of complete medium and cultured for variable lengths of time in 24-well plates (Falcon Labware) in a humidified incubator containing $5 \%$ $\mathrm{CO}_{2}$. Cells were cultured either in the absence of any stimulus or in the presence of plate-bound anti-CD3 mAb (OKT3) or soluble anti$\mathrm{CD} 2 \mathrm{mAb}\left(\mathrm{T} 11_{2}\right.$ and $\left.\mathrm{T} 11_{3}\right)$. The anti-CD3 was obtained as murine ascites produced by the hybridoma cell line OKT3 (American Type Culture Collection, Rockville, MD) and was affinity-purified using protein $\mathrm{G}$ columns (Pierce, Rockford, IL). The anti-CD2 Ab pair $\left(\mathrm{T} 11_{2}\right.$ and $\mathrm{T} 11_{3}$ ) were provided by Dr. Ellis Reinherz (Dana Farber Cancer Institute, Boston, MA). Anti-CD3 $\mathrm{mAb}$ was used under crosslinking conditions, i.e., culturing cells in wells precoated with $\mathrm{Ab}$ (anti-CD3 at $10 \mu \mathrm{g} / \mathrm{ml}$ in carbonate buffer). Anti-CD2 Ab pair (T11 and $\mathrm{T} 11_{3}$ ) were used in soluble form at 1:1000 final dilution.

In some experiments, different cytokines or $\mathrm{Ab}$ against cytokines were added to cultures. Recombinant human IL-2, IL-4, TNF- $\alpha$ and rabbit anti-human polyclonal $\mathrm{Ab}$ against the same cytokines were obtained from Genzyme Corp. (Boston, MA) and used in culture at the following concentrations: IL-2, $25 \mathrm{U} / \mathrm{ml}$; IL-4, $25 \mathrm{ng} / \mathrm{ml}$; TNF- $\alpha, 5$ $\mathrm{ng} / \mathrm{ml}$; rabbit anti-human IL-2 polyclonal antibody, $12.5 \mu \mathrm{g} / \mathrm{ml}$; rabbit anti-human IL-4 polyclonal neutralizing, $5 \mu \mathrm{l} / \mathrm{ml}$. Anti-TAC mAb (gift of Dr. T. Waldmann, National Cancer Institute, Bethesda, MD) was added at a final concentration of $10 \mu \mathrm{g} / \mathrm{ml}$ to cultures containing anti-human IL-2 Ab to ensure an efficient blockade of IL-2 utilization. IFN- $\gamma$ and rabbit anti-human IFN- $\gamma$ polyclonal $\mathrm{Ab}$ were a kind gift of Dr. M. Capobianchi (Department of Virology, Università La Sapienza, Rome) and were used at a final concentration of $200 \mathrm{IU} / \mathrm{ml}$ and 500 Neutralizing Units/ml, respectively. Recombinant human IL-7 was obtained by PeproTech, Inc (Rocky Hill, NJ) and used at final concentration of $10 \mathrm{ng} / \mathrm{ml}$. Recombinant human IL-15 was obtained by Genzyme Corp. and used at a final concentration of $50 \mathrm{ng} / \mathrm{ml}$. Cytokine concentrations were chosen to mimic the average amount detectable in the stimulated LP T cell culture as assessed in previous studies, and anti-cytokine $\mathrm{Ab}$ were added at a final concentration three times higher than the concentration able to neutralize the average estimated production of each cytokine under stimulation.

In some experiments, $\mathrm{T}$ lymphocytes were preincubated for $1 \mathrm{~h}$ at $37^{\circ} \mathrm{C}$ with a blocking anti-Fas IgG mAb (final concentration, $500 \mathrm{ng} / \mathrm{ml}$ ) (clone ZB4; Medical and Biological Laboratories Co., Ltd., Nagoya, Japan) which blocks apoptosis by a second anti-Fas IgM mAb (clone CH-11; Upstate Biotechnology Inc., Lake Placid, NY). Apoptosis induced by CH-11 anti-Fas mAb (final concentration, $200 \mathrm{ng} / \mathrm{ml}$ ) was also evaluated. Phenotypic expression of Fas $\mathrm{Ag}$ (CD95) was assessed either on freshly isolated and cultured LP T cells by flow cytometric analysis using anti-Fas mAb-PE conjugated (clone UB2; MBL).

Assessment of apoptosis. Apoptosis was measured by flow cytometry as previously described (16). Briefly, at the end of the culture period, cells were washed twice in PBS and resuspended in hypotonic fluorochrome solution (propidium iodide $50 \mu \mathrm{g} / \mathrm{ml}$ [Sigma Chemical Co.] in $0.1 \%$ sodium citrate plus $0.1 \%$ Triton X-100), kept $4-8 \mathrm{~h}$ at $4^{\circ} \mathrm{C}$ in the dark, and analyzed by FACScan cytofluorimeter. Percentage of apoptotic cells was determined by evaluating hypodiploid nuclei after proper gating on DNA content according to previous studies $(16,17)$.

Apoptosis was also assessed using acridine orange/ethidium bromide fluorescence staining (18), and by direct fluorescence detection of digoxigenin-labeled genomic DNA. This was accomplished by labeling $3^{\prime}-\mathrm{OH}$ termini of apoptosis-associated DNA strand breaks with digoxigenin-conjugated dUTP using terminal deoxynucleotidyl transferase (Apop Tag ${ }^{\mathrm{TM}}$; Oncor. Gaithersburg, MD).

IFN- $\gamma$ measurement. The amount of IFN- $\gamma$ production by $0.5-1$ $\times 10^{6} \mathrm{LP}$ T cells after $24 \mathrm{~h}$ of culture was measured by ELISA using commercially available kits (R\&D Systems Inc., Minneapolis, MN) following manufacturer's instructions.

\section{Results}

LP T cells manifest increased apoptosis in the unstimulated state and when stimulated via the CD2 signaling pathway. In initial studies, we determined the susceptibility of PBMC and LPMC to apoptosis in the unstimulated state and following stimulation via different $T$ cell activation pathways. In these and subsequent studies, apoptosis was assessed by FACScan analysis of cellular DNA content after staining with propidium iodide (PI) (see Methods), unless otherwise indicated.

We showed that unstimulated LPMC manifested a greater percentage of apoptotic cells when compared to PBMC; thus as shown in Fig. 1, the percentage of apoptotic cells in culture after $18 \mathrm{~h}$ was two- to threefold greater in LPMC cultures than PBMC cultures $(P<0.001$ by the unpaired Student's $t$ test). These differences in the percentage of apoptotic cells are not the result of the LPMC isolation procedure, as similar treatments do not induce apoptosis of PBMC (data not shown). This difference also extended to stimulated cell populations. As also shown in Fig. 1, while TCR/CD3 pathway-stimulated LPMC and PBMC (cells stimulated with anti-CD3 mAb; see Methods) manifested the same percentage of apoptotic cells after $18 \mathrm{~h}$ culture as their unstimulated counterparts, CD2 pathway-stimulated LPMC (stimulated with a pair of anti-CD2 antibodies, see Methods) contained a significantly greater fraction of cells in apoptosis than unstimulated LPMC $(P<0.01)$, whereas CD2 pathway-stimulated PBMC did not contain a significantly higher fraction of cells in apoptosis than unstimulated PBMC. Finally, because up to $90 \%$ of LP T cells are CD45R0+ (19) we determined apoptosis in purified PB 


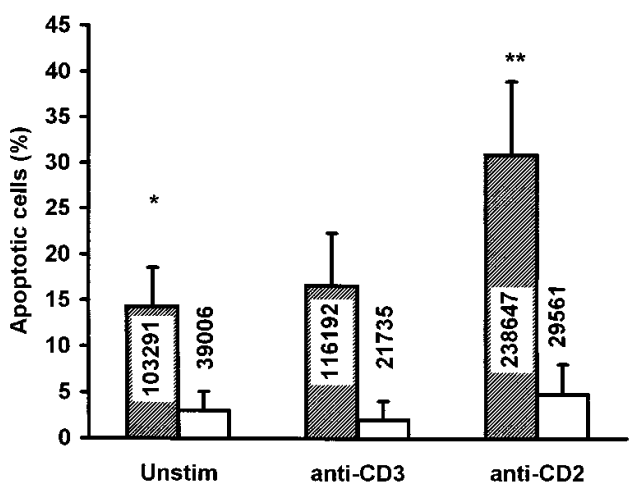

Figure 1. Relative proportion of apoptotic LPMC and PBMC after $18 \mathrm{~h}$ of culture with different stimuli. Relative proportion of apoptotic cells was quantitated by propidium iodide staining of nuclei followed by FACS analysis. Values represent mean $\pm 1 \mathrm{SD}$ from five different experiments $(* P<0.001$ unstimulated LPMC vs. unstimulated PBMC by unpaired Student's $t$ test. ** $P<0.01 \mathrm{CD} 2$ pathway-stimu-

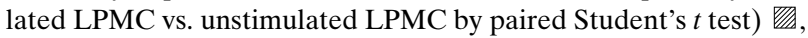
LPMC; $\square$, PBMC. Values in columns represent the mean of the absolute numbers of apoptotic cells per culture (obtained by multiplying the cell yield from the culture by the percentage of apoptotic cells as determined by PI staining).

CD45R0 + T cells so as to compare apoptosis in phenotypically equivalent cell populations. We found that apoptosis in CD2 pathway-stimulated CD45R0+ PB T cells was similar to that of whole PBMC and far lower than that of LPMC; thus, the difference in apoptosis between LPMC and PBMC was not due to a difference in CD45R0 positivity. These differences were observable also when the absolute numbers of apoptotic cells per culture were evaluated (Fig. 1).

The differences between LPMC and PBMC apoptosis could not be attributed to differences in the proliferative response of these $\mathrm{T}$ cell populations. Thus, as shown previously as well as in Fig. 2 of the present study, cells in PBMC populations mount considerably greater proliferative responses than cells in LPMC populations, both after TCR/CD3 and CD2 pathway stimulation. However, the level of apoptosis did correlate with proliferation within the LPMC population, because TCR/CD3 pathway stimulation in this and previous studies in-

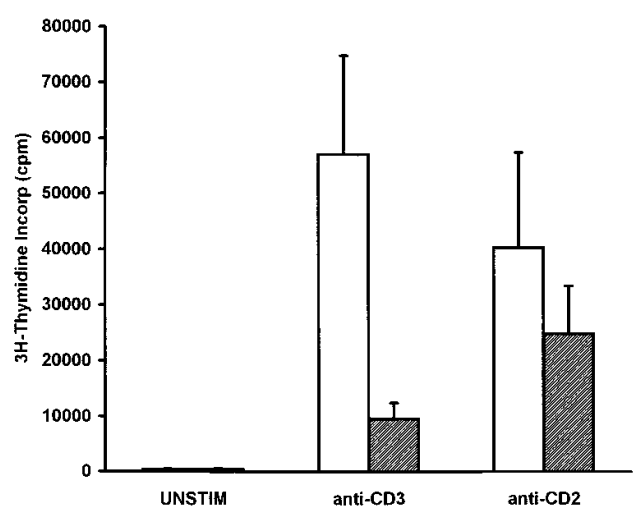

Figure 2. Proliferation of PBMC and LPMC after $72 \mathrm{~h}$ of culture with different stimuli. Values represent mean $\pm 1 \mathrm{SD}$ from three different experiments. 爵, LPMC; $\square$, PBMC.
Table I. Relative Proportion of Apoptotic LP T Cells After $24 \mathrm{~h}$ of Culture with Different Stimuli

\begin{tabular}{lccc}
\hline & PI & TUNEL & $\begin{array}{r}\text { Acridine orange/ } \\
\text { ethidium bromide }\end{array}$ \\
\hline Unstimulated & $22 \pm 4$ & $26 \pm 3$ & $9 \pm 5$ \\
CD3 pathway-stimluated & $25 \pm 6$ & $28 \pm 2$ & $10 \pm 6$ \\
CD2 pathway-stimulated & $48 \pm 8$ & $41 \pm 3$ & $29 \pm 4$
\end{tabular}

Apoptosis was quantitated by propidium iodide (PI) staining, followed by FACS analysis, by TUNEL technique and by acridine orange/ethidium bromide fluorescence staining. Values represent mean \pm 1 SD from three different experiments.

duced far less proliferation than did CD2 pathway stimulation. Results similar to those above were obtained in studies using purified LP T cells. Moreover, similar results were obtained when apoptotic cells were identified in the same experiments using PI uptake, Tunel technique and acridine orange/ethidium bromide uptake (Table I).

Time course of CD2 pathway-induced apoptosis of LPT cells. The above results could reflect differences in the time course of apoptosis rather than the overall level of apoptosis obtained under the various culture conditions. We therefore performed time course studies to determine if differences were observed over a full stimulation cycle. As shown in Fig. 3, only a low percentage of $\mathrm{T}$ cells were apoptotic upon initial isolation $(<5 \%)$, but this increased rapidly in both unstimulated and in CD2 pathway-stimulated cells. The percentage of apoptotic cells peaked at $24-48 \mathrm{~h}$ and plateau at $72 \mathrm{~h}$. At all time points, the percentage of cells exhibiting apoptosis was greater in CD2 pathway-stimulated cell cultures than in unstimulated cells. These results indicate that differences in the apoptotic potential of LP T cells were not merely due to a different time course of apoptosis.

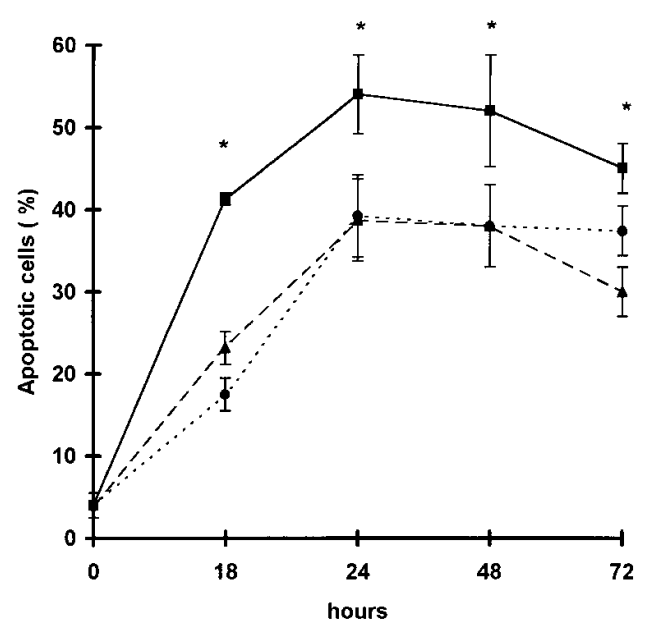

Figure 3. Percentage of apoptotic LP T cells at different time points after anti-CD3 or CD2 stimulation. Relative proportion of apoptotic cells were quantitated by propidium iodine staining of nuclei followed by FACS analysis. Values represent mean \pm 1 SD from three different experiments. ( ${ }^{*} P<0.01 \mathrm{CD} 2$ pathway-stimulated T cells vs. unstimulated T cells). $\mathbf{\square}, \mathrm{CD} 2$ pathway-stimulated T cells; $\boldsymbol{\Lambda}, \mathrm{CD} 3$ pathway-stimulated T cells; $\bullet$, unstimulated $\mathrm{T}$ cells. 


\begin{tabular}{lcll}
\hline & \% Apoptotic cells & & \\
\hline Unstimulated & $31 \pm 3$ & CD2 pathway-stimulated & Apoptotic cells \\
Unstimulated + IL-2 & $20 \pm 3^{\ddagger}$ & anti-CD2 + IL-2 & $44 \pm 5$ \\
Unstimulated + IL-4 & $29 \pm 2$ & anti-CD2 + IL-4 & $46 \pm 6$ \\
Unstimulated + IFN- $\gamma$ & $30 \pm 2$ & anti-CD2 + IFN- $\gamma$ & $45 \pm 3$ \\
Unstimulated + TNF- $\alpha$ & $40 \pm 6$ & anti-CD2 + TNF- $\alpha$ & $45 \pm 3$ \\
Unstimulated + anti-IL-2 & $55 \pm 5^{\S}$ & anti-CD2 + anti-IL-2 & $46 \pm 6$ \\
Unstimulated + anti-IL-2 & $37 \pm 6$ & anti-CD2 + anti-IL-4 & $47 \pm 2$ \\
Unstimulated + anti-IFN- $\gamma$ & $43 \pm 7$ & anti-CD2 + anti-IFN- $\gamma$ & $45 \pm 4$ \\
Unstimulated + anti-TNF- $\alpha$ & $28 \pm 3$ & anti-CD2 + anti-TNF- $\alpha$ & $43 \pm 2$ \\
& & & $46 \pm 2$ \\
\hline
\end{tabular}

*LP T cells were cultured for $48 \mathrm{~h}$ in the presence or absence of anti-CD2 mAb. Data represent mean $\pm 1 \mathrm{SD}$ of three different experiments. ${ }^{\ddagger} P=$ 0.002 Unstimulated + IL-2 vs. Unstimulated. ${ }^{\circledR} P=0.01$ Unstimulated + anti-IL-2 vs. Unstimulated.

CD2 pathway-induced apoptosis of LP T cells cultured in the presence of lymphokines and cytokines. The tendency of LP T cells to undergo apoptosis could conceivably be influenced by various lymphokines and cytokines that have previously been shown to affect apoptosis; accordingly, we measured LP T cell apoptosis in cells cultured in the presence of various lymphokines and cytokines or their respective antibodies. As shown in Table II, culture of unstimulated LP T cells in the presence of various regulatory lymphokines or antibodies to these lymphokines showed that IL-2 had a sparing effect on apoptosis, i.e., there was less apoptosis in the presence of IL-2 ( $P=0.002$ by the paired Student's $t$ test) and more apoptosis in the presence of anti-IL-2 compared with baseline $(P=0.01$ by the paired Student's $t$ test). IL 15 seems to induce similar changes in unstimulated but not in CD2-pathway stimulated LP T cells (unstim + IL-15: 27 \pm 5 ; anti-CD2 stimulated+IL-15: $47 \pm 8$ ). In contrast, culture of unstimulated LP T cells in the presence of IL- 4 or IFN- $\gamma$ had no effect on apoptosis. Finally, culture of cells in the presence of the inflammatory cytokine TNF- $\alpha$ marginally enhanced apoptosis in unstimulated cells and had no effect on apoptosis of stimulated cells. It should be noted, however, that anti-TNF- $\alpha$ did not inhibit apoptosis of either the unstimulated or stimulated cell population. Recently, it has been demonstrated that IL-7 is produced by intestinal epithelial cells (20). IL-7 has been shown to inhibit apoptosis in IL-2 deprived T cell clones (21). We found in two out of three experiments, a decrease in the percentage of apoptosis adding IL-7 to unstimulated cells. IL-7 did not affect the CD2pathway stimulated LP T cell apoptosis (unstim+IL-7: 29 \pm 5 ; antiCD2 stimulated+IL-7: 45.5 \pm 7 ).

CD2 pathway-induced apoptosis is mediated by Fas signaling. In previous studies, we observed that LP and PB CD45R0 + T cells coexpress surface Fas to the same extent (85-90\%). These CD45R0+/Fas + cell populations differed, however, in that LP CD45R0+/Fas + cells manifested greatly increased levels of apoptosis following cross-linking of Fas with anti-Fas mAb than PB CD45R0+/Fas + cells (19). Thus, levels of Fas expression did not account for levels of apoptosis. In the present study, we extended these findings with studies designed to determine the role of surface Fas in apoptosis associated with CD2-pathway cell stimulation. In these studies, apoptosis mediated via surface Fas was assessed making use of an IgM anti-Fas mAb (clone $\mathrm{CH}-11$ ) which induces apoptosis via Fas antigen as well as an IgG1 anti-Fas mAb (clone ZB4) which blocks Fas-antigen-mediated apoptosis.

As shown in Fig. 4, IgM anti-Fas (CH-11) mAb augments apoptosis in unstimulated cells (baseline apoptosis), and this effect is blocked by the IgG1 anti-Fas mAb (ZB4); IgG1 antiFas does not, however, block baseline apoptosis. These studies show that unstimulated cells are indeed susceptible to increased apoptosis mediated by Fas signaling; however, they are indeterminate with regard to whether baseline apoptosis is Fas-mediated, since the cells may have received a Fas signal in vivo which cannot be blocked by antibody in vitro. As also shown in Fig. 4, CD2 pathway-stimulation augments apoptosis and such enhanced apoptosis is blocked by preincubation of cells with IgG1 anti-Fas mAb. On the other hand, such enhanced apoptosis is not further increased by incubation with IgM anti-Fas mAb (data not shown). Similar results were obtained when apoptosis was detected by the TUNEL technique (data not shown). Thus, the augmented apoptosis that follows CD2 pathway stimulation is mediated by Fas signaling.

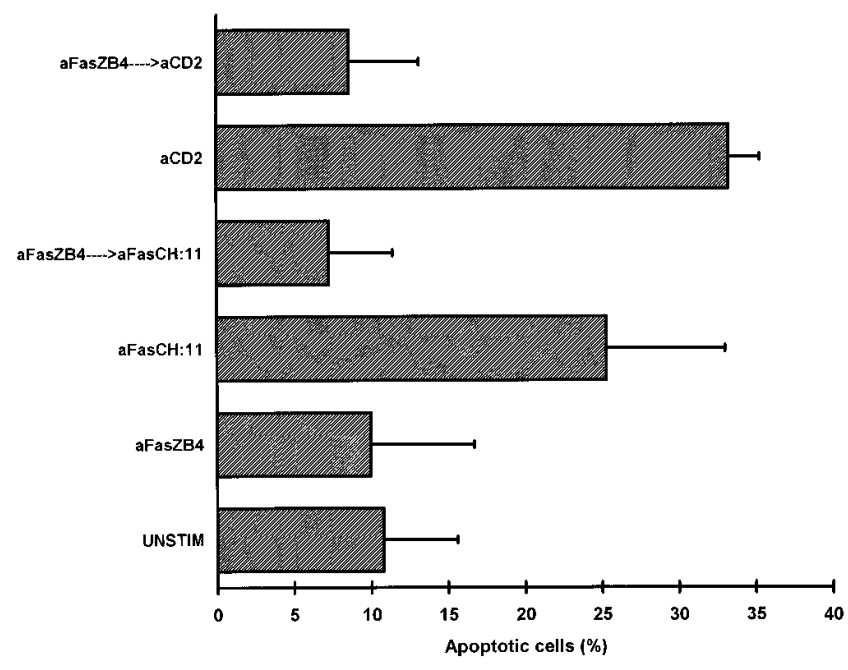

Figure 4. Effect of Fas blockade on CD2-mediated apoptosis. Assessment of apoptosis by acridine orange/ethidium bromide fluorescence staining after $24 \mathrm{~h}$ of culture. Values represent mean $\pm 1 \mathrm{SD}$ from two different experiments. 


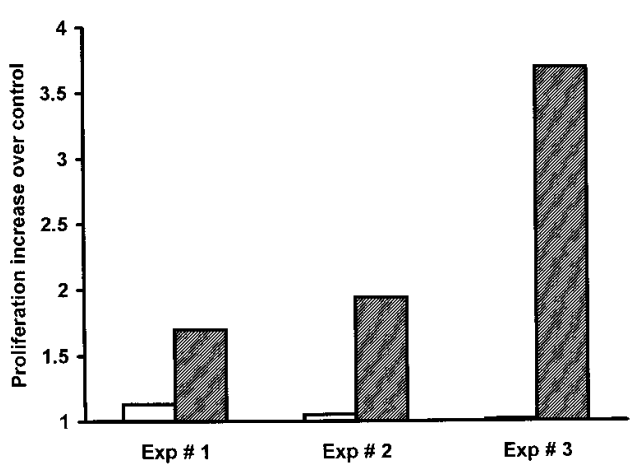

Figure 5. Effect of apoptosis blockade on CD2-induced LP T cell proliferation. Blockade of apoptosis was accomplished by using a IgG1 anti-Fas mAb (ZB4) as in Fig. 4. Three different experiments are represented. $\square$, aFasZB4 $\rightarrow$ Unstim/unstim; 局, aFasZB4 $\rightarrow$ $\mathrm{aCD} 2 / \mathrm{aCD} 2$.

Functional consequence of CD2 pathway apoptosis. In a final series of studies we tested the proposition that the inhibition of apoptosis in CD2-pathway stimulated LP T cells should lead to improved cell survival and thus increased cytokine production capacity. Accordingly, we stimulated LP T cells via the CD2pathway in the absence and in the presence of IgG1 (ZB4) anti-Fas $\mathrm{mAb}$ (to inhibit CD2 pathway-induced apoptosis) and then tested proliferation by thymidine incorporation and/or the culture supernatants for the presence of IFN- $\gamma$. As shown in Fig. 5, LP T cells preincubated with ZB4 anti-Fas $\mathrm{mAb}$ and stimulated by $\mathrm{CD} 2$ pathway showed an increased proliferation when compared to the CD2 pathway stimulated cells. Moreover, significantly more IFN- $\gamma$ was produced by cell cultures in which apoptosis was inhibited (Table III). These studies thus show that apoptosis has a downregulatory effect on $\mathrm{T}$ cell proliferation and lymphokine production.

\section{Discussion}

In the present study we demonstrated that unstimulated LP T cells manifest an increased susceptibility to apoptosis in comparison with PB T cells. In addition, whereas this increased baseline level of apoptosis is not further increased when the cells are cultured with a TCR/CD3 pathway stimulant, antiCD3, it is increased when the cells are cultured with a CD2 pathway stimulant, an anti-CD2 antibody pair. This pattern of apoptosis is not strictly related to proliferation: $\mathrm{PB} \mathrm{T}$ cells mount more vigorous proliferative responses than LP T cells yet manifest a far lower level of apoptosis and TCR/CD3 pathway stimulation does not augment the level of apoptosis al-

Table III. Effect of Apoptosis Blockade on CD2-induced LP T Cell IFN- $\gamma$ Production

\begin{tabular}{lrrrrrr}
\hline Experiment... & 1 & 2 & 3 & 4 & 5 & 6 \\
\hline Unstim & 2 & 51 & 10 & 8 & 11 & 21 \\
aFasZB4 $\rightarrow$ Unstim & 10 & 34 & 2 & 8 & 6 & 65 \\
aCD2 & 286 & 138 & 125 & 1058 & 46 & 170 \\
aFasZB4 $\rightarrow$ aCD2 & 498 & 276 & 170 & 1528 & 184 & 201
\end{tabular}

Values are expressed as pg/ml. $P<0.05$ by paired Student's $t$ test: aFasZB4 $\rightarrow$ aCD2 vs. aCD2. though it induces some proliferation. Nevertheless, there is some correlation with proliferation in that CD2 pathway stimulation induces more LP T cell proliferation than does TCR/ CD3 pathway stimulation and this increased proliferation is in rough proportion to the increased level of apoptosis. We conclude that one or more apoptotic mechanisms are more activated in unstimulated LP T cells and that these mechanisms are further activated by CD2 pathway stimulation. Since LP T cells show an increased capacity to secrete cytokines as compared to $\mathrm{PB} T$ cells-especially when triggered via the CD2 stimulation pathway $(12,13)$-the increased apoptotic cell death that follows CD2 pathway stimulation would be predicted to be an important mechanism of downregulating LP T cell cytokine production that might otherwise induce inflammation in the lamina propria; this indeed proved to be true in that LP T cell in cultures in which apoptosis was inhibited produced significantly increased amount of IFN- $\gamma$.

Insight into the origin of increased apoptosis in LP T cells comes from previous studies of the functional state of such cells with respect to cell activation and cytokine secretion. We and others have shown that LP T cells are relatively unresponsive to stimulation via the TCR/CD3 signaling pathway but retain considerable capacity to proliferate in response to stimulation via the CD2 signaling pathway (10-12). In addition, despite the fact that LP T cells have increased expression of IL-2R, they do not proliferate when cultured in IL-2 (12). One can therefore suggest that LP T cells are T cells that have been rendered partially anergic, if one defines the latter via TCR/ CD3 unresponsiveness. Evidence in favor of this view is the fact that culture of LP T cells in the absence of stimulants and in the presence of IL-2 brings about a substantial return of responsiveness (12), just as culture in IL-2 reverses anergy in murine $\mathrm{T}$ cell clones (22). In addition, Boussiotis et al. have shown in recent studies that human peripheral $\mathrm{T}$ cells intentionally rendered anergic and then cultured in IL-2 become much like LP T cells, in that they respond to TCR/CD3 stimulation only if costimulated via CD2. These investigators have also shown that whereas fully anergic $\mathrm{T}$ cells do not express a signaling CD2 epitope upon stimulation, anergic cells cultured in IL-2 do express this epitope upon stimulation, accounting for the recovered CD2-mediated proliferative capacity (23).

Previous studies have shown that while anergic T cells recover responsiveness when cultured under certain conditions, they may also undergo apoptosis under other conditions. This is shown most clearly in recent studies in which it was shown that superantigen immunization of mice is marked by cell proliferation followed by an anergic state and cell deletion (apoptosis) $(5,6)$. Thus, while the mechanisms relating anergy to apoptosis is unknown, it is clear that anergic $\mathrm{T}$ cells are more susceptible to apoptotic cell death. These considerations lead to the view that the tendency of LP T cells to undergo apoptosis is related to their partially anergic state. In support of this concept is the observation that IL-2, a lymphokine that we have shown previously tends to return unstimulated LP T cells to a more responsive state, also decreases apoptosis in such T cells. Of interest, IL-2 did not affect apoptosis in CD2 pathway stimulated cells. This is consistent with prior observations showing that IL-2 does not reverse unresponsiveness in LP $\mathrm{T}$ cells under conditions of stimulation (12). Finally, it should be noted that this effect of IL-2 is somewhat at odds with recent data showing that restimulated $\mathrm{T}$ cells, exposed to high amount of IL-2 undergo increased apoptosis (24). This para- 
dox, however, is resolved by the likelihood that the effect of IL-2 on apoptosis depends greatly on the preexisting state of cell activation. Thus, in nonanergic, fully responsive $\mathrm{T}$ cells, reactivation in the presence of IL-2 may lead to apoptosis, whereas in partially anergic, relative unresponsive cells (cells already prone to apoptosis) the presence of IL-2 may lead to reduced anergy and thus reduced apoptosis.

Relative to the mechanism of apoptosis in LP T cells, we showed in a previous study that while unstimulated and comparable PB and LP T cell populations (CD45R0+ cells) expressed equal amount of Fas only the LP T cells are susceptible to apoptosis via surface Fas cross-linking (19). This observation indicated that Fas is a necessary but not sufficient condition to Fas-mediated apoptosis. This observation also suggested that Fas signaling, triggered in vivo by Fas ligand, may account for increased apoptosis in LP T cells in parallel with previous findings in human T cell hybridomas and CD3activated human PB T cells (25-28). In the present study we obtained direct evidence for this possibility by showing that blocking of the Fas-Fas ligand interaction with an anti-Fas $\mathrm{mAb}$ abolished the increased apoptosis obtained via CD2 pathway stimulation. Fas signaling may also account for the increased apoptosis of unstimulated cells, but the data here do not address this possibility because the unstimulated cells may have been stimulated via Fas in vivo and thus could not be blocked by the IgG1 anti-Fas mAb in vitro. Further studies on the effects of infusion of anti-Fas antibody in vivo on LP T cells will be necessary to further explore this possibility.

The observation that LP T cells exhibit increased Fasmediated apoptosis yet display no increase in Fas expression is entirely compatible with previous studies in which it was shown that apoptosis following Fas-Fas ligand interaction does not depend solely on the display of these molecules, but also on the acquisition of a cellular phenotype that supports a Fasmediated apoptosis signal $(7,29,30)$. Similarly, they are consistent with the fact that the consequence of Fas signaling is variable, leading to cell activation in some circumstances and cell death in others $(31,32)$. We would therefore conclude that Fas pathway signaling in LP T cells is associated with a yet unknown downstream change that render LP T cells susceptible to apoptosis. This view is supported by the recent observation that Fas signaling in LP T cells activates the acidic sphyngomyelinase pathway leading to a ceramide product whereas it does not in PB T cells (19).

Another apoptosis mechanism that may operate in LP T cells is that mediated by TNF- $\alpha$. The gene encoding the TNF- $\alpha$ receptor is in the same family as the Fas gene, and both TNF- $\alpha \mathrm{R}$ and the Fas gene have similar death sequences in their intracellular domains $(33,34)$; moreover, $\mathrm{TNF}-\alpha$ can be shown to mediate apoptosis (35). Addition of TNF- $\alpha$ to resting LP T cells did enhance apoptosis in these cells, but addition of anti-TNF- $\alpha$ had no effect. Thus, from the limited data obtained here, it appears that while LP T cells are susceptible to apoptosis mediated by TNF- $\alpha$, it is unlikely that TNF- $\alpha$ accounts for apoptosis in resting LP $\mathrm{T}$ cells. In further studies, we observed that neither TNF- $\alpha$ nor anti-TNF- $\alpha$ had an effect on the enhanced apoptosis induced by CD2 pathway stimulation of LP T cells, suggesting that the $\mathrm{TNFa} / \mathrm{TNFaR}$ apoptotic pathway is not involved in the apoptosis of stimulated LP T cells. A similar observation has been made in relation to the mechanism involved in the apoptosis induced by TCR/CD3 pathway stimulation in peripheral T cells (28).
In conclusion, LP T cells exhibit a higher level of spontaneous and anti-CD2 pathway-induced apoptosis than PB T cells. This enhanced apoptosis is a feature of a cell population that displays characteristics of anergic cells and may thus be part of profile of cell function characteristic of highly stimulated, highly differentiated effector cells. Finally, the increased apoptosis observed in LP T cells appears to involve a change in the Fas signaling pathway wherein Fas stimulation has a heightened capacity to cause apoptosis.

\section{Acknowledgments}

This work was supported in part by a grant from Istituto Superiore di Sanità. Research Project: Prevenzione dei fattori di rischio della salute materno-infantile.

R. De Maria is a recipient of a AIRC fellowship.

\section{References}

1. Pallone, F., S. Fais, O. Squarcia, L. Biancone, P. Pozzilli, and M. Boirivant. 1987. Activation of peripheral and intestinal lamina propria lymphocytes in Crohn's disease. "In vivo" state of activation and "in vitro" response to stimulation as defined by the expression of early activation antigens. Gut. 28:745-753.

2. Peters, M.G., H. Secrist, K.R. Anders, G.S. Nash, S.R. Rich, and R.P. MacDermott. 1989. Normal human intestinal lymphocytes. Increased activation compared with the peripheral blood. J. Clin. Invest. 83:1827-1831.

3. Fiocchi, C. 1989. Mucosal immunity. Gastroenterol. Intl. 2:172-179.

4. Brandtzaeg, P., T.S. Halstesen, K. Kett, P. Krajci, D. Kvale, T.O. Rognum, H. Scott, and L.M. Sollid. 1989. Immunobiology and immunopathology of human gut mucosa: humoral immunity and intraepithelial lymphocytes. Gastroenterology. 97:1562-1586.

5. Renno, T., M. Hahne, and H.R. MacDonald. 1995. Proliferation is a prerequisite for bacterial superantigen-induced $\mathrm{T}$ cell apoptosis in vivo. J. Exp. Med. 181:2283-2287.

6. Galelli, A., M. Delcourt, M.-C. Wagner, W. Peumans, and P. TruffaBachi. 1995. Selective expansion followed by profound deletion of mature $\mathrm{Vb} .3^{+} \mathrm{T}$ cells in vivo after exposure to the superantigenic lectin Urtica dioica agglutinin. J. Immunol. 154:2600-2611.

7. Kabelitz, D., T. Pohl, and K. Pechold. 1993. Activation induced cell death (apoptosis) of mature peripheral T lymphocytes. Immunol. Today. 14:338-339.

8. Wesselborg, S., O. Janssen, and D. Kabelitz. 1993. Induction of activation-driven death (apoptosis) in activated but not resting peripheral blood $\mathrm{T}$ cells. J. Immunol. 150:4338-4345.

9. Savill, J., V. Fadok, P. Henson, and C. Haslett. 1993. Phagocyte recognition of cells undergoing apoptosis. Immunol. Today. 14:131-136.

10. Pirzer, U.C., G. Schurmann, S. Post, M. Betzler, and S.C. Meuer. 1990. Differential responsiveness to CD3-Ti vs. CD2-dependent activation of human intestinal T lymphocytes. Eur. J. Immunol. 20:2339-2342.

11. Qiao, L., G. Schurmann, M. Betzler, and S. C. Meuer. 1991. Activation and signaling status of human lamina propria T lymphocytes. Gastroenterology. 101:1529-1536.

12. Boirivant, M., I. Fuss, C. Fiocchi, J.S. Klein, S.A. Strong, and W. Strober. 1996. Hypo-proliferative human lamina propria T cells retain the capacity to secrete lymphokines when stimulated via the CD2/CD28 accessory signaling pathways. Proc. Assoc. Am. Physicians. 108:55-67.

13. Targan, S.R., R.L. Deem, M. Liu, S. Wang, and A. Nel. 1995. Definition of lamina propria $\mathrm{T}$ cell responsive state. Enhanced cytokine responsiveness of T cells stimulated through the CD2 pathway. J. Immunol. 154:664-675.

14. Fuss, I.J., M. Neurath, M. Boirivant, J.S. Klein, C. de la Motte, S.A. Strong, C. Fiocchi, and W. Strober. 1996. Disparate CD4 ${ }^{+}$Lamina Propria (LP) lymphokine secretion profiles in inflammatory bowel disease. Crohn's disease LP cells manifest increased secretion of IFN-gamma, whereas ulcerative colitis LP cells manifest increased secretion of IL-5. J. Immunol. 157:1261-1270.

15. Bull, D.M., and M.A. Bookmann. 1977. Isolation and functional characterization of human mucosal lymphoid cells. J. Clin. Invest. 59:966-974.

16. Cifone, M.G., R. De Maria, P. Roncaioli, M.R. Rippo, M. Azuma, L.L. Lanier, A. Santoni, and R. Testi. 1994. Apoptotic signaling through CD95 (Fas/ APO-1) activates an acidic sphingomyelinase. J. Exp. Med. 180:1547-1552.

17. Zamai, L., E. Falcieri, G. Zauli, A. Cataldi, and M. Vitale. 1993. Optimal detection of apoptosis by flow cytometry depends on cell morphology. $C y$ tometry. 14:891-897.

18. Duke, R.C., and J.J. Cohen. 1992. Morphological and biochemical assays of apoptosis. In Current Protocols in Immunology. J.E. Coligan, A.M. Kruisbeek, D.H. Margulies, E.M. Shevach, W. Strober, editors. Greene Publishing Associates, Inc., and J. Wiley \& Sons, Inc. 1-3.

19. De Maria, R., M. Boirivant, M.G. Cifone, P. Roncaioli, M. Hahne, J. 
Tschopp, F. Pallone, A. Santoni, and R. Testi. 1996. Functional expression of Fas and Fas ligand on human gut lamina propria $\mathrm{T}$ lymphocytes: a potential role for the acidic sphingomyelinase pathway in normal immunoregulation. $J$. Clin. Invest. 97:316-322.

20. Watanabe, M., Y. Ueno, T. Yajima, Y. Iwao, M. Tsuchiya, H. Ishikawa, S. Aiso, T. Hibi, and H. Ishii. 1995. Interleukin 7 is produced by human intestinal epithelial cells and regulates the proliferation of intestinal mucosal lymphocytes. J. Clin. Invest. 95:2945-2953.

21. Hernandez-Caselles, T., M. Martinez-Esparza, D. Sancho, G. Rubio, and P. Aparicio. 1995. Interleukin-7 rescues human activated T lymphocytes from apoptosis induced by glucocorticosteroids and regulates bcl-2 and CD25 expression. Hum. Immunol. 43:181-189.

22. Beverly, B., S. Kang, M. Lenardo, and R. Schwartz. 1992. Reversal of in vitro T cell clonal anergy by IL-2 stimulation. Int. Immunol. 4:661-667.

23. Boussiotis, V.A., G.J. Freeman, J.D. Griffin, G.S. Gray, J.G. Gribben, and L.M. Nadler. 1994. CD2 is involved in maintenance and reversal of human alloantigen-specific clonal anergy. J. Exp. Med. 180:1665-1674.

24. Lenardo, M.J. Interleukin-2 programs mouse alpha beta T lymphocytes for apoptosis. 1991. Nature (Lond.). 353:858-861.

25. Dhein, J., H. Walczak, C. Baumler, K.-M. Debatin, and P.H. Krammer. 1995. Autocrine $\mathrm{T}$ cell suicide mediated by APO-1/(Fas/CD95). Nature (Lond.). 373:438-441.

26. Brunner, T., R.J. Mogil, D. LaFace, N.J. Yoo, A. Mahboubi, F. Echeverri, S.J. Martin, W.R. Force, D.H. Lynch, C.F. Ware et al. 1995. Cell-autonomous Fas(CD95)/Fas-ligand interaction mediates activation-induced apoptosis in T cell hybridomas. Nature (Lond.). 373:441-444.

27. Yu, S.T., D.J. Panka, H. Cul, R. Ettinger, M. El-Khatib, D.H. Sherr, B.Z. Stanger, and A. Marshak-Rothstein. 1995. Fas(CD95)/FasL interactions required for programmed cell death after T cell activation. Nature (Lond.). 373: 444-448.

28. Alderson, M.R., T.W. Tough, T. Davis-Smith, S. Braddy, B. Falk, K.A. Schooley, R.G. Goodwin, C.A. Smith, F. Ramsdell, and D.H. Lynch. 1995. Fas ligand mediates activation-induced cell death in human T lymphocytes. J. Exp. Med. 181:71-77.

29. Miyawaki, T., T. Uehara, R. Nibu, T. Tsuji, A. Yachie, S. Yonehara, and N. Taniguchi. 1992. Differential expression of apoptosis-related Fas antigen on lymphocyte subpopulations in human peripheral blood. J. Immunol. 149:37533758

30. Klas, C., K.M. Debatin, R.R. Jonker, and P.H. Krammer. 1993. Activation interferes with the APO-1 pathway in mature human T cells. Int. Immunol. 5:625-630.

31. Alderson, M.R., R.J. Armitage, E. Maraskovsky, T.W. Tough, E. Roux, K. Schooley, F. Ramsdell, and D.H. Lynch. 1994. Fas transduces activation signals in normal human T lymphocytes. J. Exp. Med. 178:2231-2235.

32. Ucker, D.S., J. Meyers, and P.S. Obermiller. 1992. Activation-driven $\mathrm{T}$ cell death. II. Quantitative differences alone distinguish stimuli triggering nontransformed T cell proliferation or death. J. Immunol. 149:1583-1592.

33. Tartaglia, L.A., T. M. Ayres, G.H.W. Wong, and D.V. Goeddel. 1993. A novel domain within the $55 \mathrm{Kd}$ TNF receptor signals cell death. Cell. 74:845-853.

34. Smith, C.A., T. Farrah, and R.G. Goodwin. 1994. The TNF Receptor Superfamily of cellular and viral proteins: activation, costimulation and death. Cell. 76:959-962.

35. Zheng, L., G. Fisher, R.E. Miller, J. Peschon, D.H. Lynch, and M.J. Lenardo. 1995. Induction of apoptosis in mature T cells by tumour necrosis factor. Nature (Lond.). 377:348-351. 